$\operatorname{cocos}(1997), 12,01$ - 17

Printed in Sri Lanka

\title{
ASSESSMENT OF THE EFFECTS OF ENVIRONMENTAL FACTORS ON YIELD OF COCONUT (Cocos nucifera, $L_{\text {. }}$ )
}

\author{
TS G Peiris ' and RO Thattil ${ }^{2}$ \\ 1 Coconut Research Institute, Lunuwila. Sri Lanka \\ 2 University of Peradeniya, Sri Lanka.
}

\begin{abstract}
The long-term nut yield data.and climate data of eight variables (19761992) were analyzed to understand the effects of climate and weather on the yield variability between picks. The yield variation over the years had no systematic pattern. The order of contribution of the picks to total yield is not significantly consistent between years. Explanatory models were developed at monthly lag periods prior to harvest of each pick. The most and least influential picks in respect of climate variability are picks 5 and 2 respectively. The critical period with respect to climate and weather variability of picks $1-6$ are February, June, July, September, December and February respectively. The climatic models fitted at these periods explain the yield variability between picks. The influence of climatic variables during these periods vary from pick to pick. Maximum air temperature and relative humidity in the afternoon are the two most significant environmental variables influencing yield irrespective of picks.
\end{abstract}

\section{INTRODUCTION}

The coconut yield is harvested in six picks within a year at bi-monthly intervals. Pick 1 is scheduled during the latter part of January, pick 2 during the latter part of March, and so on. Development cycle of coçonut takes 44 months of which the flower primordium takes about 32 months to emerge ('non-visual cycle') and the period of the last 12 months ('visual cycle') represents fertilization of the female flowers to development into mature nuts (Menon \& Pandalai, 1958). Thus the effects of climate and weather are evident at all stages of development cycle and significantly involved in the production of nuts. 
Peiris et. al., (1995) showed that the previous studies on the agroclimatological aspects of coconut have not been adequately addressed and were not able to explain the yield variation between-and-within years. Also, these studies in Sri Lanka were confined to the effects of rainfall alone on annual yield. It is therefore necessary to study the impact of different environmental factors on pick-wise yields separately to acquire more information.

Accordingly in this paper exploratory techniques are used to find the effect of different environmental variables on crop yields, to identify the most influential periods for each pick with respect to climate variability, and to understand yield variability between picks.

\section{SECONDARY DATA}

The yield per hectare (158 palms/ha) of the six harvests (picks) from 1976 to 1992 from Bandirippuwa Estate $\left(7^{\circ} 20^{\prime} \mathrm{N} ; 7^{\circ} 53^{\prime} \mathrm{E} ; 30.5 \mathrm{~m}\right)$ of the Coconut Research Institute (CRI), Lunuwila were used. The estate is located in the Low Country Intermediate Zone, $\mathrm{IL}_{1}$ (75\% expectancy values of annual rainfall $>1500 \mathrm{~mm}$ ). The major soil type of the estate is latteritic gravel.

The climatic data consisted of the daily records of rainfall (RF), pan evaporation (EV), sunshine duration (SS), wind velocity at $3 \mathrm{~m}(\mathrm{WV})$, minimum air temperature (TMIN), maximum air temperature (TMAX), relative humidity in forenoon (RHAM) and relative humidity in afternoon (RHPM) from 1976 to 1992 from the Bandirippuwa Estate (BE). The data were obtained from the agro-meteorological station maintained by the division of Biometry of the CRI. The rainfall ( $\mathrm{mm}$ ), evaporation ( $\mathrm{mm}$ ), and sunshine duration (hrs/d) were measured using the rainfall gauge, Class A evaporation tank and Campbell-Stokes sunshine recorder respectively. The wind velocity $(\mathrm{km} / \mathrm{d})$ was measured from the anemometer at $3 \mathrm{~m}$ height.

The minimum and maximum air temperatures $\left({ }^{\circ} \mathrm{C}\right)$ were recorded in a Stevenson Screen using mercury and alcohol-in-glass thermometers respectively at $08: 30$ and 15:30 hrs daily. Both relative humidity $(\%)$ in the forenoon and afternoon were obtained by transforming the current dry and wet bulb temperatures recorded respectively in the screen at 08:30 and 15:30 hrs using ventilated mercury-in-glass psychrometer. 


\section{ANALYSIS OF YIELD AND CLIMATE}

Yield Analysis in Figure 1.

Temporal variation of pick-wise data over the 17 years period is shown

The analysis of autocorrelation coefficients of the series confirmed that there were no systematic patterns in any of the series and the year-toyear variation was accounted for by the climatic and weather variability due to the various climatic elements. Of the six picks, changes in the yield pattern over the years in pick 3 closely followed, those of the annual yield $\left(r=0.947^{* * *}\right)$. The yield data were analyzed using the nested type linear model and it was found that the variation of yield between picks was nearly five times the variation of yield between years. The yields were significantly different between years and between picks. It was found that the ranking order of picks based on the long-term means was $P_{3}^{\prime}>P_{4}>P_{2}>P_{3}>P_{1}>P_{6}$ (where $P_{i}$ is the yield of $i^{\text {th }}$ pick \& $i=1,2, . ., 6$ ). This order was significantly different between years indicating that the order was not consistent for different years. Thus, in studying the effects of climate and weather on yield, models was fitted for each pick separately.

Based on the long-term data the percentage contribution from the individual picks to the annual yield can be taken as $12,20,24,20,14$, and 10 percent for picks 1 - 6 respectively.

\section{Climate Analysis}

The eight climatic variables RF, RF-EV, SS, WV, TMIN, TMAX, RHAM, and RHPM were analyzed separately on monthly basis. The monthly variability of the mean, $25 \%$ percentile $\left(Q_{1}\right)$, and $75 \%$ percentile $\left(Q_{3}\right)$ of each variable is shown in Figure 2.

The monthly rainfall varied from around $35 \mathrm{~mm}$ (January) to 310 $\mathrm{mm}$ (November). The time series plot of monthly data confirmed the existence of two peaks within a year. The two peaks corresponded with the two monsoon seasons expected in $\mathrm{IL}_{1}$ during May and June from south-west $\dot{m}$ onsoon rains and during. October and November from the second intermonsoon rains (Fig. 2a). More than $65 \%$ of the annual rainfall is accounted for by these four months. The $75 \%$ expectancy of annual rainfall at the CRI was $1600 \mathrm{~mm}$. The monthly evaporation rate varied from $95 \mathrm{~mm}$ in 

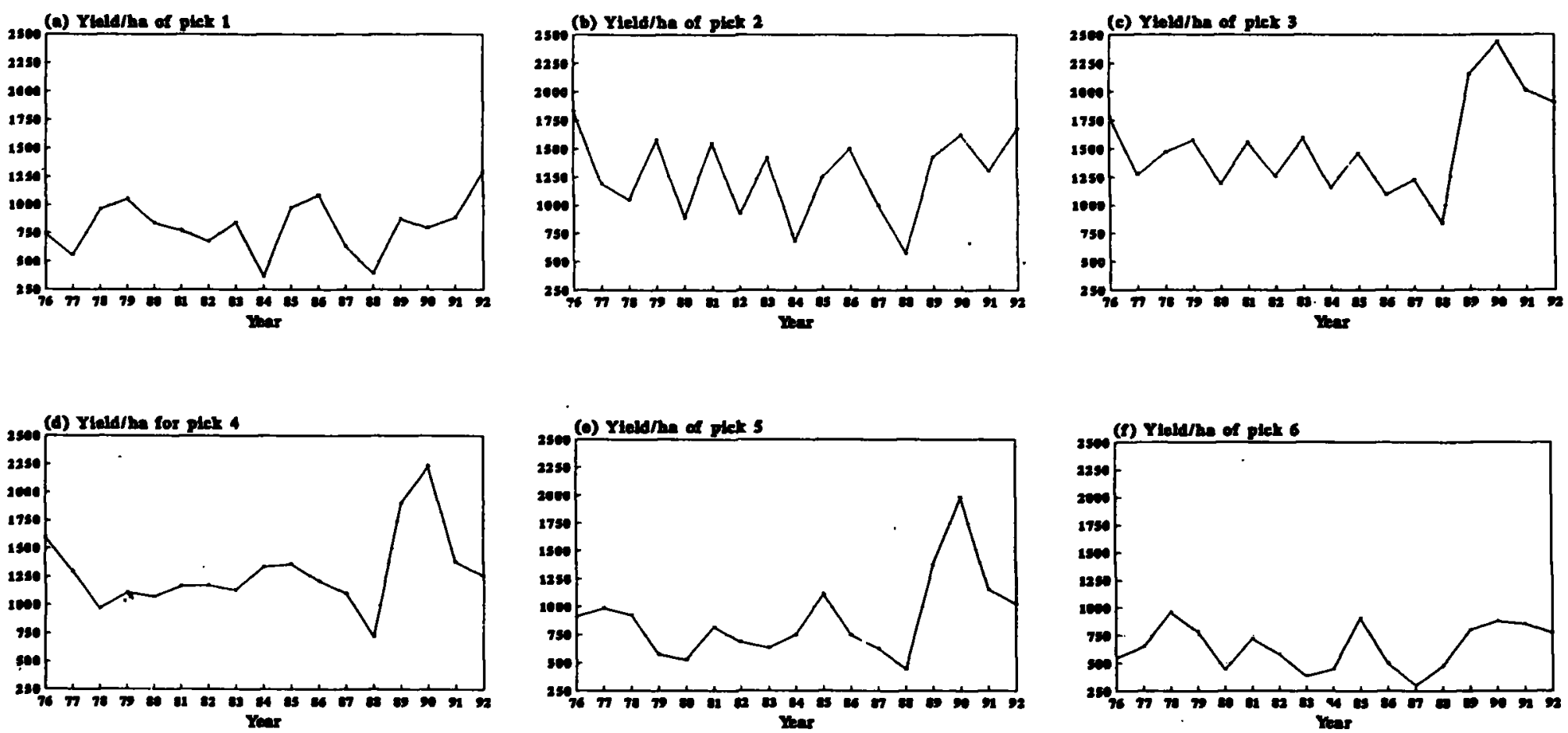

Figure 1. Temporal variation of the yield of picks 1 - 6 

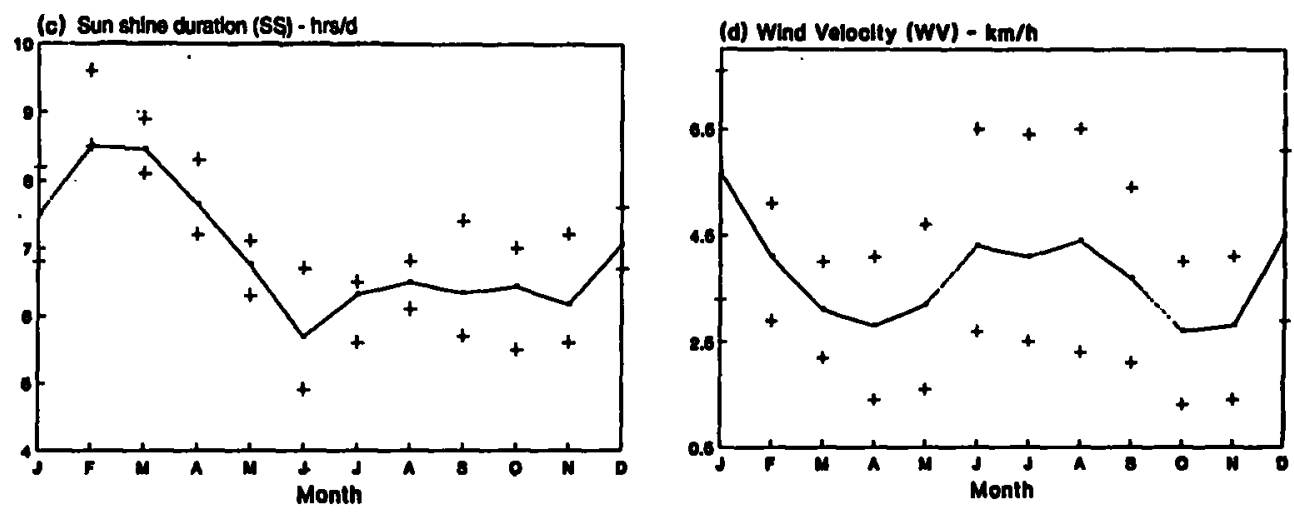

(a) Raln lal (AF) - mm
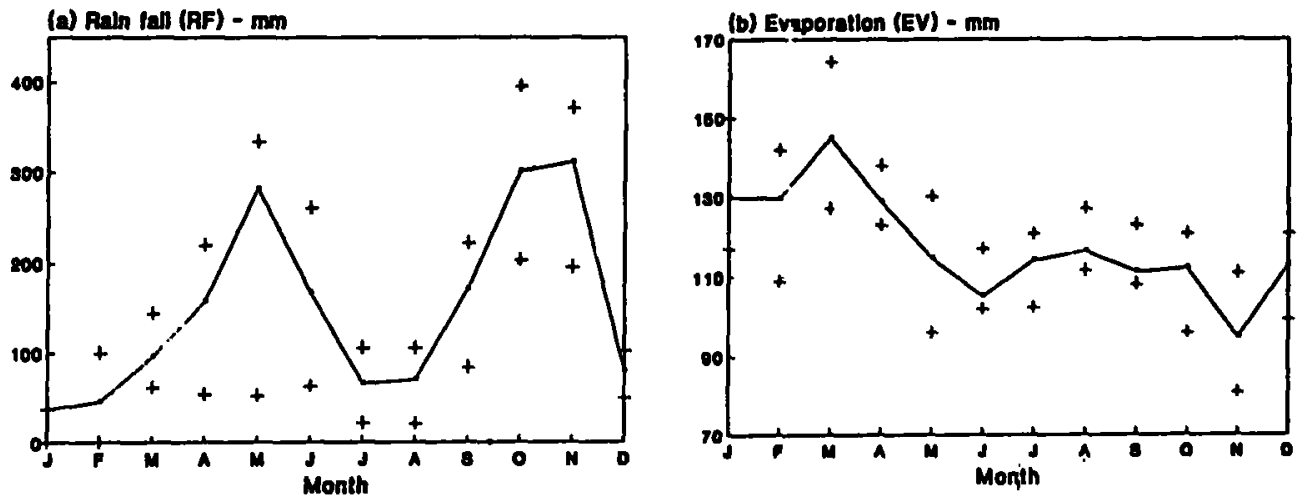

Figure 2. Monthly variation mean (.), Q1 (t), and Q3 (t) of the eight climatic variables namely

(a) RF, (b) RF-EV, (c) SS, (d) WV, (e) TMIN

(f) TMAX, (g) RHAM and (i) RHPM 

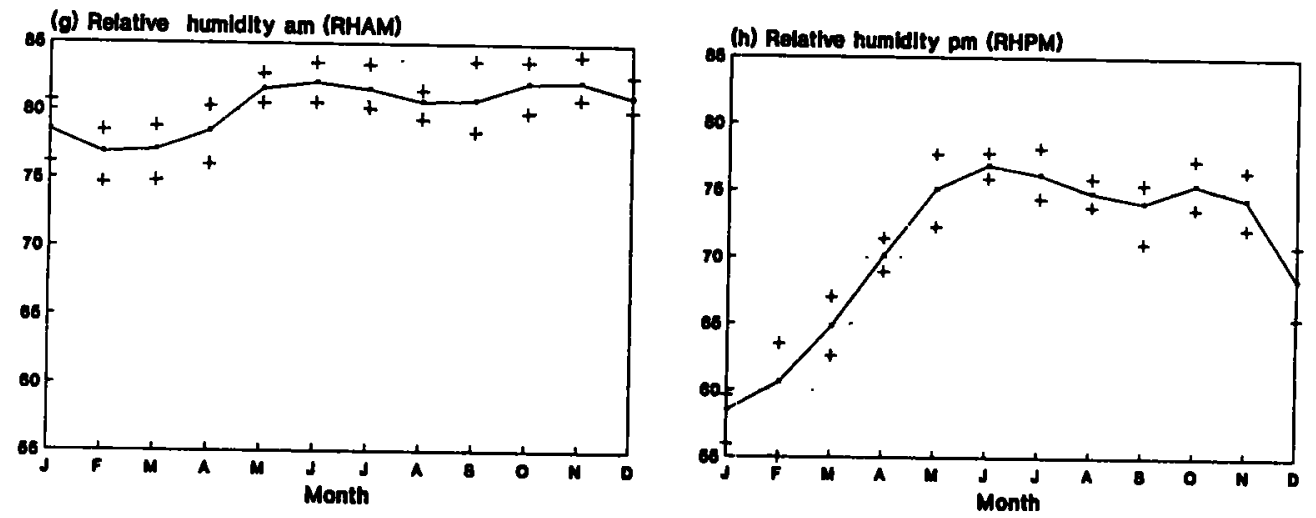

(o) Min. Temperature (TMIN) - C

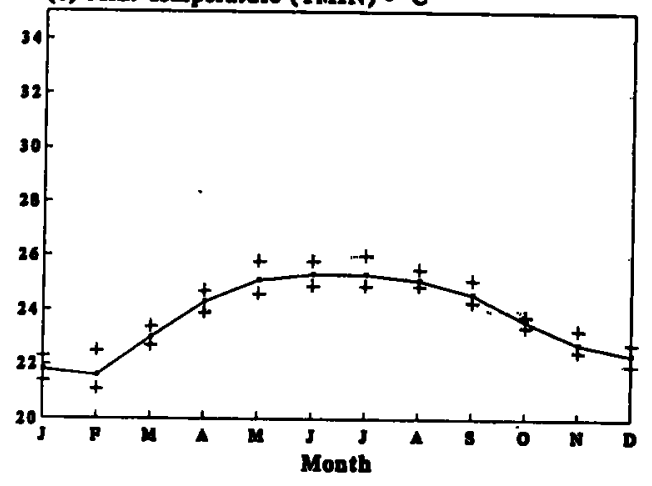

(f) Max. Temperature (TMAX) - C

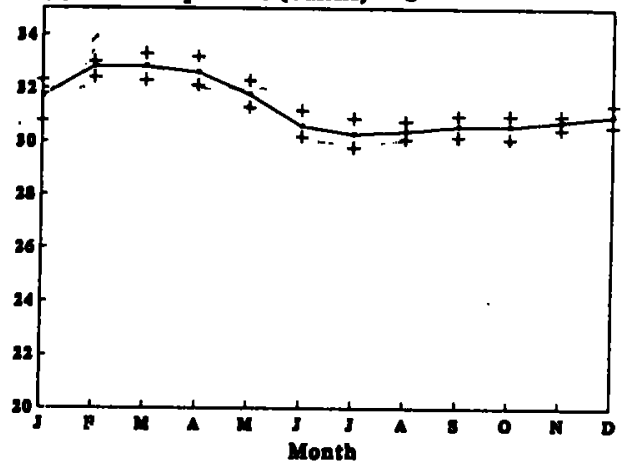

Figure 2. (Contd) 
November to $145 \mathrm{~mm}$ in March. It was found that in three years out of four the evaporation exceeded rainfall in the months of January, February, March, July, August, and December (Fig. 2b). These months can be considered.as dry months.

The sunshine duration was highest during February and March. It decreased in the range of 9 to $5 \mathrm{hrs} / \mathrm{d}$ from February to June. The mean sunshine duration during July to November remained virtually constant in the range of 6 to $7 \mathrm{hrs}$ per day. The wind velocity varied from around $6 \mathrm{~km} /$ $\mathrm{hr}$ in January to about $4.5 \mathrm{~km} / \mathrm{hr}$ in October and November.

The maximum air temperature varied from around $33^{\circ} \mathrm{C}$ in February and March to about $30^{\circ} \mathrm{C}$ in July and August, while the minimum air temperature varied from around $25^{\circ} \mathrm{C}$ in June and July to $22^{\circ} \mathrm{C}$ in January and February. It was also noticed that the variation of mean air temperature throughout the year was very low with a maximum of about $28^{\circ} \mathrm{C}$ in April and a minimum of about $27^{\circ} \mathrm{C}$ in December, but the mean diurnal temperature between months fluctuated and was in the range of $5-11^{\circ} \mathrm{C}$. The relative humidity in the morning fluctuated around $80 \%$ during the year and in the afternoon rose from January to July in the range of around $60-75$ per cent and thereafter it was virtually constant around $75 \%$.

The saturation vapour pressure was estimated using the formulae given by Smith (1991). The monthly mean of daily vapour pressure deficit at the CRI was $1.36( \pm 0.40) \mathrm{kPa}$. It varies from $1.0 \mathrm{kpa}$ during June to about 2.0 kpa during January and February.

\section{MODELLING}

Of the 44 months duration development cycle, up to 36 months prior to harvest of each pick (that is, from the nine months after the time inflorscences open to the time of harvest) was considered in the analysis, as the climate impact of months further away is assumed to be less influential. This period was divided into 36 equal months. Equal intervals were taken as lags 1 to 36 where lag 1 is referred as the period during the first month before the harvest, ilag 2' as the period during the second month before the harvest, and so forth. As an example, the pick 1 is harvested during the latter part of January thus the lags 1 and 2 of pick 1 were taken as December and November in the previous year respectively. Similarly the pick 6 is harvested during the latter part of November thus the lags 1 and 2 of pick 6 were considered as October and September of the same year respectively. 
Solar radiation at the CRI has a very strong linear relationship with the sunshine duration (Peiris \& Thattil, 1995). Therefore sunshine duration was considered in modelling instead of solar radiation. Let $R_{i j} S S_{i j}, E V_{i j}$, $\mathrm{W}_{\mathrm{ij}}, \mathrm{TMIN}_{\mathrm{ij}}$, TMAX $_{\mathrm{ij}}$, RHAM $_{\mathrm{ij}}$, and RHPM $\mathrm{ij}_{\mathrm{ij}}$ be the corresponding variables of RF, SS, EV, WV, TMIN, TMAX, RHAM, and RHPM respectively at the $\mathrm{j}^{\text {th }} \operatorname{lag}(\mathrm{j}=1,2, \ldots, 36)$ of the $\mathrm{i}^{\text {th }}$ pick $(\mathrm{i}=1,2, \ldots 6)$ (say, $\left.\mathrm{L}_{\mathrm{ij}}\right)$. The linear models such as, $P_{i}=f\left(R_{i j}, S S_{i j}, E V_{i j}, W V_{i j}, T_{M N}, T_{i j}, T_{i j}, R_{A M}, R_{i j} H P M_{i j}\right)$ were fitted to each $L_{i j}$ using Statistical Analysis System (SAS, 1987). As no information is available about the pattern of the response of climatic variables on yield, linearity of model was assumed. The maximum $R^{2}$ improvement technique was used to develop models (Peiris and Thattil, 1994).

The significant variables and $\mathbf{R}^{2}$ for each model were tabulated separately for picks. The results showed that the significant variables vary among lags within a pick and among picks within a lag. It indicates that the important climatic variables influencing yield depend upon the time of development and the time of inflorescence opening. Some models explained the yield variability adequately while other models were inadequate to explain a sufficient amount of the yield variability. The main climatic variables influencing the yield of coconut for specific periods: (a) during 36 months prior to harvest, and (b) during 12 months prior to harvest were evaluated.

\section{During 36 months prior to harvest}

When all the variables are considered together the influence of climatic variables for a given period is decided based on the total number of times a variable entered the models (significant occurrences) fitted to each lag during the specified period. Of the 216 models for 36 lags of each pick, WV had an exceptionally higher number of significant occurrences than other variables. The TMAX and RF also had high significant occurrences followed by RHPM and SS. The number of significant occurrences of the other three variables were lower than that of SS, but within these three it did not differ much. Irrespective of picks the order of importance of the climatic variables is WV $>$ TMAX $>$ RF $>$ RHPM $>$ SS $>$ EV $>$ TMIN $>$ RHAM. - The variables were ranked within picks too and it was found that the order of significantly influential variables varied from pick to pick, but WV and TMAX are the two most influential variables in all the picks.

\section{During 12 months prior to harvest}

The results during the visual cycle indicated that the total number of 
significant occurrences of the six picks was exceptionally higher in TMAX followed by SS and RHPM. The total number of significant occurrences did not differ much between RHPM, and RF, and also between EV and WV. Irrespective of picks the order of importance during the visual cycle is TMAX $>\mathrm{SS}>\mathrm{RHPM}=\mathrm{RF}>\mathrm{EV}=\mathrm{WV}>\mathrm{TMIN}>\mathrm{RHAM}$. It was also found that the order of variables varied from pick to pick during the visual cycle as well, but TMAX was the most influential variable during the visual cycle of each pick. WV which was the most important variable with 36 lags does not figure prominently in lags within 12 months.

\section{Assess the overall impact of climate on picks}

From the models fitted to each lag it was found that 'best fitting models' $\left(R^{2} \quad 0.75 ; P<0.05\right)$ varied from pick to pick. But, the overall impact of climate and weather during the 36 months cannot be assessed based on the best fitting models only. The variability explained by other models should also be considered. Further the number of significant variables also varied among models. Therefore $R^{2}$ values were weighted with respect to the residual degrees of freedom of the corresponding model to obtain a common index (Peiris, 1993a) and was named as 'weighted coefficient of multiple determination' $\left(R_{w m}^{2}\right)$. To assess the overall impact of climate on picks, the picks were ranked based on the computed $R^{2}$ and thus pick $5>$ pick $3>$ pick $4>$ pick $6>$ pick $1>$ pick 2 . It can be concluded that pick 5 is the most influential pick and pick 2 is the least influential pick, in respect of climate and weather variability prior to 36 months of each harvest. .

Based on the computed values for $\mathrm{R}^{2}$ fm for picks 1 to 6 within the visual cycle, it was found that the picks which had the highest and lowest influences in respect to climate and weather variability during the visual cycle were also fifth and second respectively.

\section{FIRST MOST INFLUENTIAL LAG (FMIL)}

The variation of $R^{2}$ over the 36 lags for each pick is shown in correlographs (see Fig. 3).

It clearly indicates that the magnitude of the correlations (for different lags) move cyclically. The lag which has the highest $R^{2}$ within the first twelve lags in a given pick corresponds to the peak of the first cycle and was defined as the 'first most influential lag' (FMIL) of that pick. Based on the 

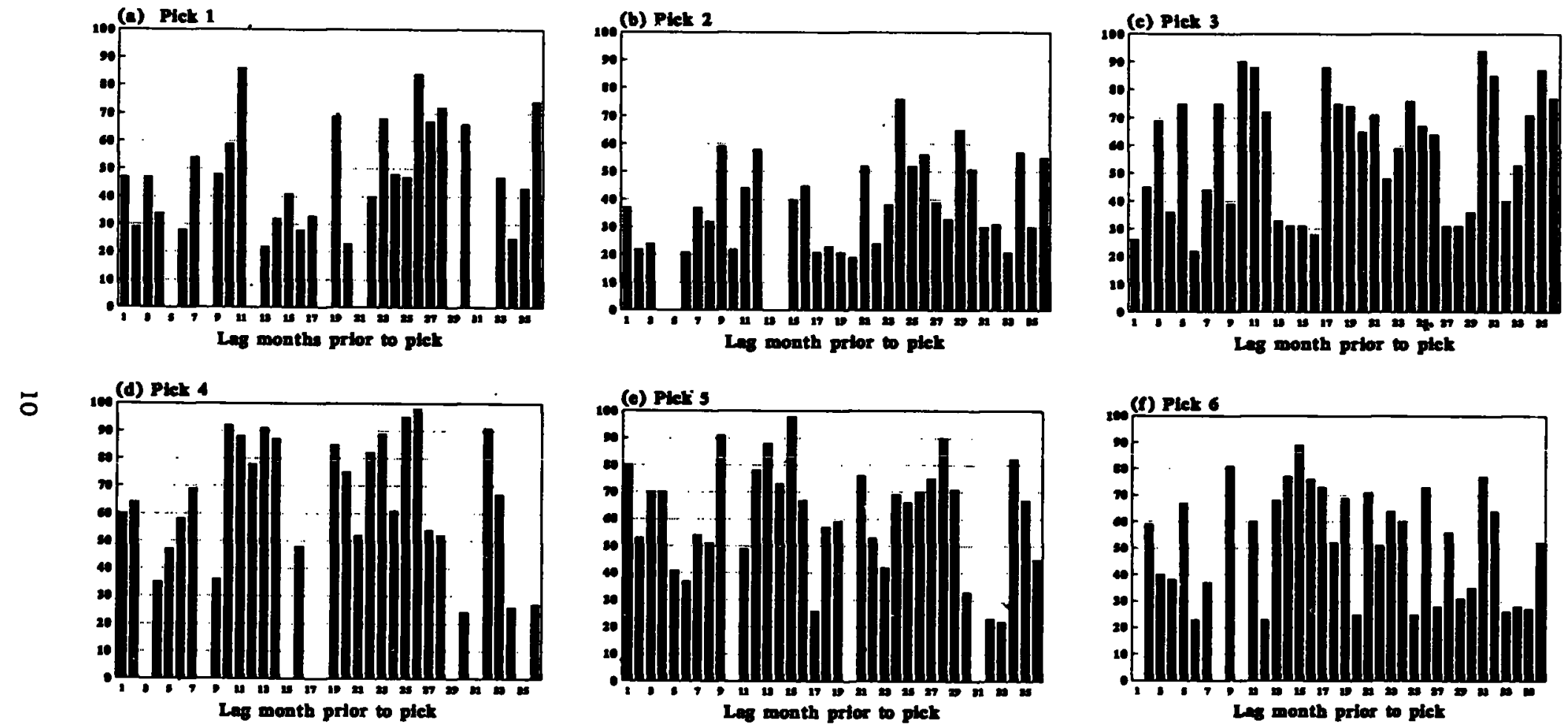

Figure 3. Correlographs for the 36 lag periods in picks 1 - 6 
trend of each correlograph shown in Figure 3 the FMIL's for each pick was identified. The significant variables for each pick was selected from the corresponding models fitted at each FMIL. The results are given in Table 1.

The results indicate that the FMIL varied from pick to pick. However, irrespective of picks it can be taken as lag 9 or 10 . This period corresponds with three to four months after fertilization of female flowers. It implies that the most critical period of any pick can be taken as between three to four months after the spathe opened. In fact Abeywardena and Mathes (1971) showed that the third and fourth months after fertilization is more critical with respect to rainfall and about $40 \%$ of female flowers were lost during this period. The results also indicate that the influencing climatic variables at the FMIL vary from pick to pick.

Table 1. First most influential lag (FMIL) and the influential climatic vari ables to the six picks

$\begin{array}{lclll}\text { Pick } & \text { FMII } & \begin{array}{l}\text { Time after } \\ \text { inflorescence } \\ \text { open }\end{array} & \begin{array}{l}\text { Month which corr- } \\ \text { esponds with FMIL }\end{array} & \begin{array}{l}\text { Influential } \\ \text { climatic } \\ \text { variables }\end{array} \\ 1 & 11 & 2^{\text {nd }} \text { month } & \text { February } & \text { EV,WV,TMN, RHPM } \\ 2 & 9 & 4^{\text {th }} \text { month } & \text { June } & \text { TMAX,RHAM } \\ 3 & 10 & 3^{\text {rd }} \text { month } & \text { July } & \text { RF,SS,WV } \\ 4 & 10 & 3^{\text {rd }} \text { month } & \text { September } & \text { RF,EV,TMIN,TMAX } \\ 5 & 9 & 4^{\text {th }} \text { month } & \text { December } & \text { EV,WV,TMAX } \\ 6 & 9 & 4^{\text {th }} \text { month } & \text { February } & \text { RF,SS,TMAX,RHPM }\end{array}$

The models developed for each pick at the respective FML explain more than $75 \%$ of the yield variability except in pick 2 which is the least influenced by the climate. The plots of the predicted values, the residuals, and upper and lower bounds of the $95 \%$ confidence interval for the mean yield of the expected values based on the models are shown in Figure 4. The fluctuation of residuals suggested that the errors were random and the normality of residuals were checked using the distribution of the standardized residuals. These results show the validity of these models to explain the impact of climate on yield variability. 

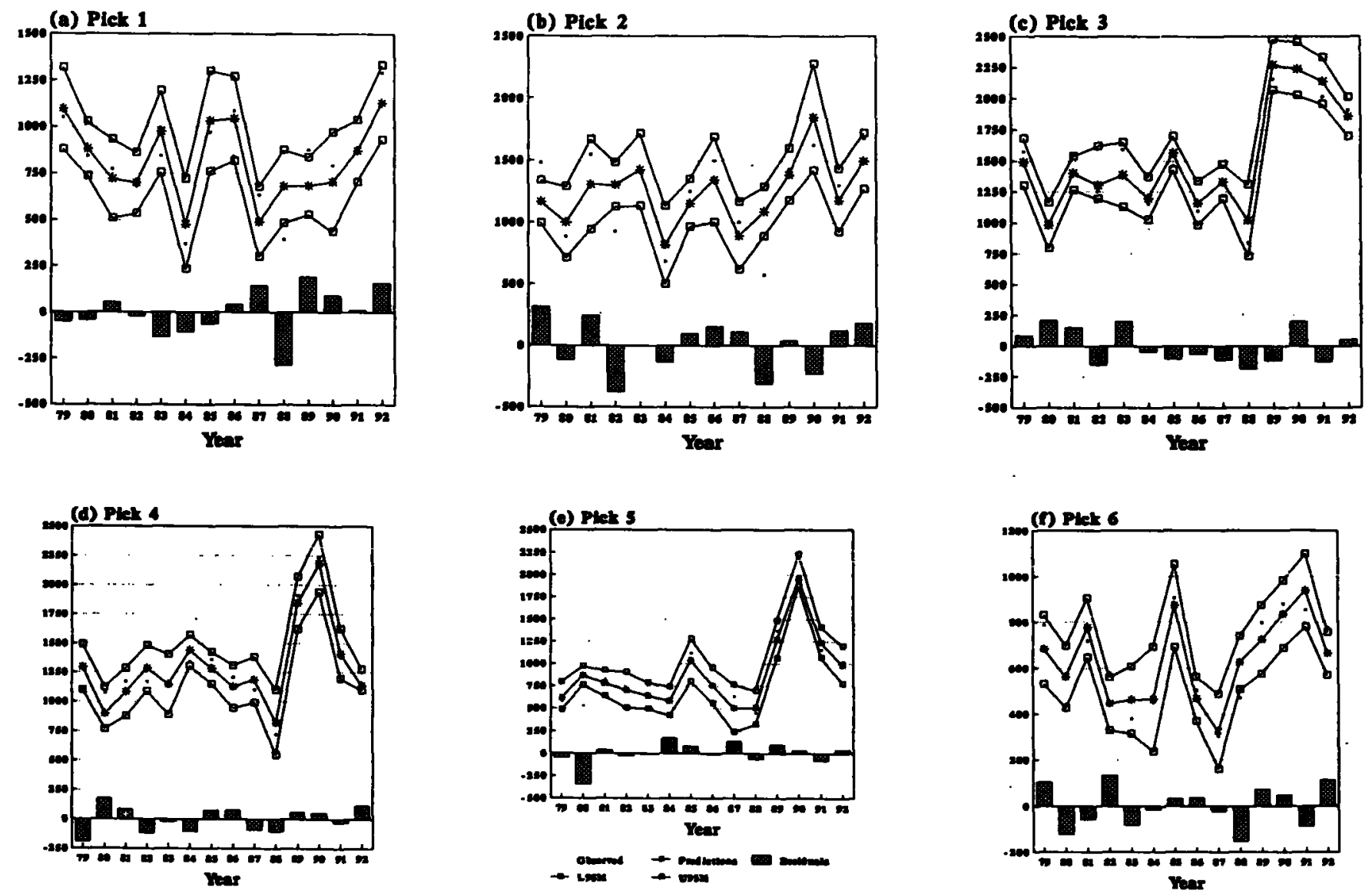

Figure 4. Plots of observed, estimated \& residual values and interquartile ranges of the mean of the estimated values based on the models 1 - 6 fitted for the yield of picks. 


\section{IMPACT OF THE CLIMATIC VARIABLES ON PICK-WISE YIELD}

The impact of climate on the pick-wise yield is explained using the models fitted at the FMIL.

Model for pick 1 at lag 11 (February)

$P_{1}=1302-15.9 E V+111.5 W V+219.3 T M I N-59.7 R H P M\left(R^{2}=0.74^{* *}\right)$

The model suggested that during February TMIN and WV had positive influence, whereas EV and RHPM had negative influence on the yield in pick 1. The TMIN and RHPM ( $\left.r=-0.77^{* * *}\right)$, and the EV and WV ( $\left.r=0.74^{* * *}\right)$ are significantly correlated. Thus it appears that low EV and high RHAM during February are beneficial in improving the yield in pick 1 .

Model for pick 2 at lag 9 (June)

$\mathrm{P}_{2}=184 \dot{8}-250.7 \mathrm{TMAX}+85.8 \mathrm{RHAM}\left(\mathrm{R}^{2}=0.53^{*}\right)$

In June TMAX and RHAM were not significantly associated. Thus it appears that the low TMAX and high RHAM are favourable in improving the yield in pick 2 .

Model for pick 3 at lag 10 (July)

$\mathrm{P}_{3}=2729+2.0 \mathrm{RF}-284.1 \mathrm{SS}+118.4 \mathrm{WV}\left(\mathrm{R}^{2}=0.90 * * *\right)$

The model suggested that the yield in pick 3 is controlled by RF, WV, and SS in July. Of them the positive coefficient of RF indicates that the presence of rains in July is favourable to increase the yield of pick 3, but the impact from rainfall will be less as July is a dry month (mean rainfall in July is about $60 \mathrm{~mm}$ ). Thus the combination of high WV and short SS during July are beneficial for the yield in pick 3 .

For pick 4 at lag 10 (September)

$\begin{aligned} P_{4}= & 20385+2.4 R F+4.8 E V+620.8 \mathrm{TMIN}-1036 \mathrm{TMAX}-49.1 \mathrm{RHPM} \\ & \left(\mathrm{R}^{2}=0.92^{* * *}\right)\end{aligned}$ 
The model suggested that during September the RF, EV, and TMIN had positive influence whereas TMAX and RHPM had negative influence. on the yield in pick 4. Most of the variables in the model are significantly inter-correlated. 'Of the five variables TMAX is the most influential variable followed by TMIN in determining the yield. The model too indicates that rain during September is favourable to improve the yield.

\section{Model for pick 5 at lag 9 (December)}

$$
P_{5}=9264+26.7 \mathrm{EV}-74.3 \mathrm{WV}-411.0 \mathrm{TMAX}+24.4 \mathrm{RHPM}\left(\mathrm{R}^{2}=0.91 * * *\right)
$$

The yield in pick 5 is positively influenced by EV and RHPM and is negatively influenced by WV and TMAX during December and of them TMAX is the most influential variable in determining the yield. The EV is significantly correlated with WV (positively) and with RHPM (negatively). It reveals that high EV and low TMAX in December are favourable to increase the yield in pick 5 .

\section{Model for pick 6 at lag 9 (February)}

$$
P_{6}=14861+1.9 R F+134.1 S S-429.0 T M A X-23.5 R H P M\left(R^{2}=0.81^{* *}\right)
$$

The model suggested that during February, RF and SS had positive influence whereas TMAX and RHPM had negative influence on yield. Of these four variables TMAX is the principal determinant of yield. It is unlikely that rainfall in February has an impact on yield of pick 6 . The RF is positively correlated with RHPM $\left(r=0.61^{*}\right)$, and SS is positively correlated with TMAX $\left(r=0.78^{* * *}\right)$. Thus it appears that the low RHPM and low TMAX during February are more favourable to increase the yield in pick 6.

\section{DISCUSSION}

Peiris et al., (1995) showed that there are many gaps in information on the effects of climate and weather on the nut yield and the growth of coconut; and multiple regression models which involve functions of various weather elements have not been attempted. Hence; the purpose of this work was to study some aspects of agroclimatology of coconut by using eight climate variables together. Multiple regression procedures were used.

As the climate is the synthesis of weather conditions in a given area, characterised by long-term statistics (mean values, variances, probabilities 
of extreme values etc.) of the meteorological elements in that area, this approach is more superior than developing models containing a single independent variable.

The study revealed that the impact of climate and the influence of climatic variables on the yield of coconut depend on the time of development of the inflorescence within picks. Of the climate variables considered in this study, maximum air temperature and relative humidity in the afternoon are the two most significant variables influencing yield irrespective of picks. The wind velocity was also identified as an important variable before the spathes open and can be due to the fact that wind velocity affects the growth of rachille (or branches) of the inflorescence. when primordium of male flowers are formed. Pick 5 has the highest impact by the climate variability followed by picks 3 and 4 . These three picks contributes about $60 \%$ of the total annual yield.

The study found that the climate during February, June, July, September, December and February are more critical periods in respect of the yields in picks 1-6 respectively and that the climate in February significantly affect the total yield. In support of the above, a study conducted on the effect of rainfall at a different location in $\mathrm{IL}_{1}$, Peiris (1993b) also found that rainfall during February is most influential on the total yield of coconut.

As high air temperature in the mornings and high evaporation during the second month of fertilization (February) do not help to retain female flowers in bunches opened during January and February (that is for 'pick 1'), yield in pick 1 will be generally low. Also high air temperature and low relative humidity in the afternoons during the fourth month of fertilization influence to increase the immatire nut fall of the bunches opened during November and December (that is for 'pick 6') and therefore the output from the pick 6 will also be low.

High relative humidity in the mornings and low air temperature in the afternoons during June are favourable for the bunches opened during March and April (that is for 'pick 2'), which suggests that more cool days during June help to reduce the immature nut fall during the fourth month of fertilization and thus the output of pick 2 will generally be high. The climate during the fourth month of fertilization (December) is also the most critical period in influencing the yield of the bunches that open during September and October (that is, for 'pick 5').Though cool days are expected during December due to occasional rains and lowest minimum air temperatures, the 
negative impact of the wind velocity and maximum temperature in December will reduce development of female flowers and increase the immature. nutfall. Consequently the yield in pick 5 will be generally lower than in pick 2.

Picks 3 and 4 are highly influenced by the climate and weather variabilities during the third month of fertilization. The rainfall during July and September show beneficial effects on picks 3 and 4 respectively and rainfall in September is more certain than the rainfall in July. Though the rainfall during September helps to retain female flowers and reduce the immature nut fall, the combination of relative humidity in the afternoons and maximum air temperature during September would tend to reduce the yield in pick 4. The month of July has the highest maximum temperature, lowest minimum temperature, low sunshine duration and high relative humidity. Thus it appears that warm and sunny days during this period coupled with more humid days with few showers help retention of tender nuts in bunches, and consequently increase the yield in pick 3.

\section{ACKNOWLEDGEMENTS}

The authors are grateful to Mr. D T Mathes, Head, Biometry Division and the staff of the Biometry Division of the CRI for their help.

\section{REFERENCES}

Abeywardena, V. and Mathes, D. T. (1971). Crop losses in coconut through button shedding and immature nutfall. Ceylon Coconut Planters Review. 6, 96-106.

Menon, K. E.V. \& Pandalai, K. M.(1958). The coconut palm - A monograph. Indian Central Coconut Committee, Ernakulam, India.

Peiris, T. S.G.(1993a).Statistical analysis of field experiments in coconut using fewer number of picks, J. of Experimental Agriculture. (29), 207- 213.

Peiris, T. S. G. (1993b). The degree of influence of rainfall on coconut. In Advances in Cocomut Research and Development, 413-420, (Eds. Nair, M. K. et al.). New Delhi:Oxford and IBH Publishing Co. Pvt. Ltd.

Peiris, T. S. G. and Thattil, R. O. (1994). Use of dimensional reduction meth ods for selection of variables in Agrometeorology dspects on coconut. 
Proceeding of the International Conference of the Royal Statistical Society. Newcastle Upon Tyne, 13-16 September.

Peiris, T. S. G. and Thattil, R. O. (1995). An alternative model to estimate solar radiation. COCOS, 9, 21-28.

Peiris, T. S. G., Thattil, R. O., \& Mahindapala, R. (1995). An analysis of the effect of climate and weather on coconut (Cocos nucifera). J. of Ex perimental Agriculture, 31 (4), 451-460.

SAS (1987). SAS/STAT Guide for personal Computers. Version 6 Edition. Cary, NC: SAS Institute Inc.

Smith, M (1991). Report on the expert consultation on procedures for revi sion of FAO guidelines for prediction of crop water requirements. FAO, Rome. 